\title{
"iUsted es comunista!". Estudios sobre clase, cultura y política en la Argentina contemporánea
}

María Patricia Pensado Leglise

Instituto de Investigaciones Dr. José María Luis Mora-CONACYT, México ppensado@institutomora.edu.mx

Pablo Pozzi, “iUsted es comunista!". Estudios sobre clase, cultura y política en la Argentina contemporánea, Buenos Aires, Prometeo, 2020, 275 pp.

El más reciente libro de Pablo Pozzi ofrece argumentaciones contundentes y sólidas de lo que considera fundamental para entender la larga tradición política de las izquierdas en su país, presente en la cultura obrera argentina, una de las más consistentes y combativas.

En once ensayos, el autor construye y deconstruye ideas en relación con el papel de las izquierdas en la formación de una cultura obrera. Si bien centra su análisis en los siglos XIX y el XX, no deja de referirse, como es común en un buen número de historiadores sociales, al presente, lo que parece explicarse debido a las voces de los trabajadores que se dan cita en sus páginas. El autor busca enfatizar el papel de la cultura como "una herramienta importantísima para contribuir a que los trabajadores se organicen y desarrollen alternativas al capitalismo" (p.19).

De entre las preguntas que Pozzi se plantea para reflexionar en relación con el tema de la cultura obrera argentina, una que me parece central es saber ¿cómo superar las innumerables resistencias, tanto propias como ajenas, que chocaban contra "la verdad aceptada", aquella que no necesita ser probada porque simplemente es así ya, sea por tradición y costumbre o por prejuicios construidos durante décadas? (p.19).

\section{c) (7) (8)}

4.0 Internacional

Secuencia. Reseñas, 2021

http://secuencia.mora.edu.mx
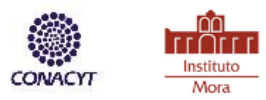
Como gran polemista que es, Pozzi contradice las interpretaciones de historiadores y científicos sociales quienes destacan el papel del peronismo en la cultura obrera y, en esa medida no se le puede considerar de izquierda; sin embargo, para el autor la izquierda no sólo se define por su filiación marxista, sino que el peronismo forma parte también de las izquierdas argentinas, ya que la cultura de izquierda se expresaba más en la subjetividad de un "sentido común" popular.

También objeta que se considere a la migración europea, que llegó en la segunda mitad del siglo XIX, como central para que las ideas de las izquierdas se propaguen e incidan políticamente en la organización de los trabajadores. Para Pozzi el asunto no tiene que ver con saber conocer cómo llegaron las diversas ideologías de izquierda a su país, sino ¿̇por qué fueron acogidas por las organizaciones de los trabajadores criollo o inmigrantes? Para responderse recurre a E. P. Thompson quien refiere el proceso de resignificación de estas ideas por la experiencia social de sus receptores, en el que intervienen "la experiencia y realidad histórica de los grupos sociales que acogieron estas ideas” (p.59). Las que configuraron una cultura popular en continua tensión con la cultura dominante, que si bien retoma idearios de la izquierda europea, va forjando un sentido propio, en el que la izquierda se define más por un comportamiento "correcto", "más una noción actitudinal que una definición ideológica precisa” (p.62).

En palabras de Pozzi: "Cada nueva generación incorpora experiencias y tradiciones, o sea costumbres, clasistas sin fisuras, aunque estas sean contradictorias [... ] los trabajadores reconocieron en ellas una representación de su realidad [...] Las ideas garibaldinas, anarquistas, socialistas, comunistas, peronistas y guevaristas fueron así una expresión de una realidad social que resurgieron una y otra vez a partir de un "sentido común" anclado en la cultura popular" (p.72).

En el capítulo 3, "El socialismo tiene que ser de izquierda ¿no? La izquierda como estructura de sentimiento en Argentina" el autor lo dedica a la reflexión sobre la entrevista, material en donde se observan siempre "elementos de subjetividad, o sea de los patrones de conducta subyacentes y de la visión del mundo del entrevistado" (p.79). Al igual que muchos historiadores u oralistas, coincide en que es una fuente que se construye, resultado de la interacción entrevistador- 
entrevistado, e influida por el contexto en la que se realiza la entrevista. Mediante un ejercicio con sus alumnos de la Universidad de Buenos Aires el autor revisa las entrevistas realizadas por la socióloga argentina Beba Váldez en 1971, durante el llamado "Vivorazo" en la ciudad de Córdoba, la que conversó con varios obreros que se definían como socialistas, y cuya visión respondía más "a un vínculo directo con su vida a través de necesidades y mejoras posibles" (p.80), que a una construcción teórica. También se consultó el Acervo del Proyecto de Historia Oral de la Universidad de Buenos Aires, revisando las entrevistas de militantes sobre su percepción del socialismo y de la revolución. La selección -apunta el autor- se centró en obreros con militancia en distintas organizaciones marxistas y peronistas, además de algunas con dirigentes y con militantes de otros sectores sociales como contraste (p.80). Su examen lo llevó a descubrir sentidos comunes a los valores que se le atribuyen al socialismo, para comprobar que el vínculo "entre lenguaje, imaginario y evocación de sentimientos contribuye a explicar la subsistencia de la izquierda orgánica a pesar de la represión" (p.80).

A partir de los entrevistados, se revelan una serie de reflexiones acerca del significado de la militancia de izquierda, resaltando el hecho de que la visión socialista todavía permanece en la clase obrera argentina lo que, a juicio del autor, tiene relación con "características particularmente argentinas (sobre) el socialismo" [...] que entronca con la ideología nacionalista del peronismo" (p.92), que a la vez tiene relación con una cultura subterránea que se nutre de continuidades con nociones religiosas o con herencias históricas revolucionarias que vincula la idea de un mundo mejor "a la existencia real y a la historia como una posibilidad real producto de la agencia humana, o sea de los rebeldes” (p.97).

En la búsqueda que emprende Pozzi para responder ¿̇cómo se estudia una cultura de clase? encuentra central desarrollar el concepto de Raymond Williams, estructura de sentimientos, que se expresa en relatos, tradiciones, testimonios en la oralidad que llega incluso a plantear un comportamiento colectivo "correcto". En sus palabras: "En la Argentina lo que se puede llamar la 'cultura', el 'sentido común', se encuentra entrelazado con conceptos tradicionalmente vinculados a nociones 
izquierdistas: lo bueno se vincula a la solidaridad, el compañerismo, el sindicato; mientras que en general los patrones son considerados explotadores” (pp.103-104).

Esta aseveración de Pozzi la ilustra con una selección de letras de canciones populares, tangos y consignas, consideradas también expresiones de la memoria colectiva que en la cultura obrera adquieren un matiz de identidad y deslinde de las clases dominantes y de los militares. Así como con algunos fragmentos de las magníficas entrevistas que contiene el libro, donde encuentra asideros suficientes para comprobar sus tesis, las cuales se pueden reconocer en las siguientes afirmaciones: "la politización parte de una explicación en torno a su realidad laboral o existencial y la educación sirve para revelar y explicar una vida ya existente” (p.171). También, "los discursos y las narraciones de cada uno de estos militantes se encuentran anclados en una cultura y un sentido común que comparte el conjunto de los trabajadores y los diferencía de otros sectores sociales" (p.178). Así como sobre la construcción de la memoria de las experiencias de lucha "como cohesión social grupal que define un 'nosotros' y un 'ellos' [ ...] y toda una concepción clasista [...] que permite la continuidad de luchas y actividades en pos de intereses clasistas" (pp.179-180).

O sobre la memoria de la derrota indica que la participación en movilizaciones obreras que son derrotadas, son asimiladas como lecciones que "se convierten en algo colectivo en una forma subconsciente pero muy poderosa” (p.257). Por ello es que la "resignificación de los triunfos y derrotas, de la lucha de clases en sí, se convierte en una conciencia de clase manteniendo una cohesión" (p.257).

El capítulo 10 es una crítica franca al reformismo y su estrategia que, en opinión del autor, tiene doble significado: “[...] refleja los intereses coyunturales de los trabajadores, especialmente en épocas de reflujo. Y sirve para disolver la auto organización del poder, volcando aun más la correlación de fuerzas a favor del capital" (p.208) y como ejemplo en la historia sindical menciona el surgimiento de la Central General de Trabajadores (CGT) y del vandorismo.

De igual manera, Pozzi crítica al parlamentarismo que considera una estrategia para ocupar espacios de poder sin proponer transformarlo y obtener reformas sin arriesgar la rentabilidad capitalista. Sin embargo, el mayor problema 
que encuentra, radica en la reforma del Estado y de su relación con la sociedad, debido a que no queda claro ni para los socialistas que contienden en las elecciones la propuesta de que la reforma se tendría que orientar a construir un Estado diferente. De ahí la crítica al comportamiento de la socialdemocracia y el populismo que "socava la utilidad y autonomía de los sindicatos como organizaciones primarias que expresan al trabajador colectivo, devaluando la identidad y la lucha de clases en un abrazo colaboracionista y corporativo" (p.213).

Ante los cambios del capitalismo debido a las recurrentes crisis económicas, la cultura obrera también ha registrado importantes transformaciones, sobre todo, en opinión del autor, en la representación del colectivo de trabajo. Es precisamente en el último capítulo que sintetiza la importancia de algunos aspectos que han sido soporte de esa cultura: la solidaridad y las rupturas, generación e identidad de clase; recomposición de clase, costumbres, tradiciones, memoria y resistencia al cambio, y si bien algunos de estos temas han sido referidos ya en el texto, en este apartado son analizados mediante los testimonios de los trabajadores. No sobra agregar que son precisamente estos aspectos los que se han ido modificando y algunos autores, entre ellos Pozzi, advierten del peligro de la anomia, posible cuando el elemento subjetivo de la esperanza de mejorar se pierde, percepción que no solo tiene relación con el poder adquisitivo, sino con la dignificación del trabajo obrero.

Para finalizar, Pozzi expone como los trabajadores ante el cambio de los patrones de acumulación del capital, hacen de las tradiciones "una trinchera para la rebelión y la resistencia a los objetivos de los empleadores [...] el concepto de "siempre lo hicimos así" se convierte en una poderosa legitimación para la protesta social" (p.255), y de resistencia cultural.

En un contexto histórico que anuncia un cambio de época, y en donde la cultura obrera no puede ser ajena a los cambios que pueden ser observados en la fragmentación habida en las luchas obreras, cuyas demandas sectoriales no se dirigen a la unidad de clase. También, en "la aceptación a nivel popular de que el desempleo, el hambre, la explotación, la corrupción estatal son parte de algo 'normal' y siempre lo serán" (p.260) opinión que limita o puede paralizar la acción política de los trabajadores y del ciudadano. 
Con todo, para el autor es claro que una forma de refutar estas ideas radica en conocer cuáles fueron los elementos que hicieron posible desarrollar una opción de izquierda y cuáles han cambiado y cómo lo han hecho. En su opinión más que desaparecer la cultura tendrá que resignificarse "en nuevas formas y sentidos comunes clasistas que sirvan a las reivindicaciones populares". (p. 261) El autor encuentra en la cultura el nexo entre experiencia y conciencia que "nos provee una forma de acceder a la subjetividad" (p.25), que permite comprender una parte importante de la complejidad del accionar humano en la praxis política.

El de Pozzi confronta y obliga a pensar en los derroteros del cambio de época, que para el conocimiento histórico y las ciencias sociales es una impronta que continuamente nos desafía, cuando las armas metodológicas que tenemos son insuficientes. Me parece que la ruta que elige el autor puede desbrozar el camino y observar con mayor claridad el horizonte.

Es posible decir que iUsted es comunista! Estudio sobre clase, cultura y política en la Argentina contemporánea es un libro imprescindible para los interesados en el estudio y la participación de las izquierdas en los movimientos sociales y la construcción de una cultura popular. Es un trabajo que incorpora al lector al diálogo con los personajes de su narrativa, lo que crea una atmosfera de proximidad lo que, pienso, es resultado de un largo camino andado por el autor en las veredas de la historia oral, lo que le ha permitido generar sensibilidad y precisión no sólo al analizar las experiencias de los sujetos, sino en su capacidad personal para describir los ambientes, produciendo el efecto de imaginar los sonidos en la tesitura de las voces de sus entrevistados con quienes, me parece, intuir el tejido de lazos solidarios y para comprobarlo recurrió a la historia oral, "donde no solo lo que decía un testimoniante era importante, sino también como lo decía y lo que no decía”. (p.20) También utilizó otras fuentes orales (canciones populares, consignas, poemas y relatos convertidos en tradición oral, entre otras). En suma, todo ese material donde los más avispados pueden encontrar la subjetividad humana, en este caso del trabajador en lucha. 